\title{
Pulses and carcinogenesis: potential for the prevention of colon, breast and other cancers
}

\author{
John C. Mathers* \\ Human Nutrition Research Centre, Department of Biological and Nutritional Sciences, University of Newcastle, \\ Newcastle upon Tyne NE1 7RU, UK
}

\begin{abstract}
Consumption of pulses as components of healthy diets is encouraged because it is believed that this is likely to help in reducing the risk of common non-communicable diseases, including cancers. However, the evidence base for the role of pulses in prevention of cancers is unconvincing because of the difficulties, using conventional epidemiological tools, in ascertaining the quantitative contribution made by pulses to cancer risk. Advances in understanding of the biological basis of cancer and of the mechanisms of action of cancer-preventing compounds offer new insights into the role of food-derived substances and of diet-gene interactions in modulating cancer risk. Pulses contain a rich variety of compounds which, if consumed in sufficient quantities, may help to reduce tumour risk.
\end{abstract}

Pulses: Cancer: Genes: Intervention studies

In many Western countries, deaths from cardiovascular disease and stroke have been declining for two to three decades or more, but there has not been a similar improvement in deaths from the other major potentially preventable cause, i.e. cancer. As a consequence, prevention of cancer mortality has risen up the political agenda and now tops the lists of targets in the UK's public health strategy Saving Lives: Our Healthier Nation (Department of Health, 1999). In the UK, the three most commonly diagnosed cancers are breast $>$ colon and rectum $>$ lung for women and lung $>$ prostate $>$ colon and rectum for men. Lung cancer rates have been falling in men but rising in women. Cancers of the breast and the prostate are on the increase in several countries including Japan, the UK and the USA (Department of Health, 1998). The present paper considers the evidence that pulses may have a role to play in the prevention of cancers at certain sites, discusses some possible antineoplastic mechanisms and suggests opportunities for further research

\section{Current public health recommendations for the prevention of cancers in respect of pulses}

In its landmark report Food, Nutrition and the Prevention of Cancer: A Global Perspective, the World Cancer
Research Fund/American Institute of Cancer Research (1997) made the following recommendations to individuals:

'Choose predominantly plant-based diets rich in a variety of vegetables and fruits, pulses (legumes) and minimally processed starchy staple foods' (Recommendation 1) and

'Eat 600-800 grams (20-30 ounces) or more than seven portions a day of a variety of cereals (grains), pulses (legumes), roots, tubers and plantains. Prefer minimally processed foods. Limit consumption of refined sugar' (Recommendation 5)

The World Cancer Research Fund/American Institute of Cancer Research (1997) noted that: 'This recommendation is consistent with, and generally supported by, but not primarily derived from, the data on cancer'. In reality, the evidence base for the role of pulses in prevention of cancers (and, therefore, for the inclusion of pulses within these recommendations) was far from convincing. The World Cancer Research Fund/American Institute of Cancer Research (1997) panel undertook a very thorough review of the relevant epidemiological literature linking intake of pulses with risk of cancer at eleven sites in the body and concluded that no judgement was possible for any site (Table 1).

Abbreviations: Ala, alanine; COX, cyclooxygenase; CRC, colorectal cancer; FAP, familial adenomatous polyposis; MnSOD, manganese superoxide dismutase; MTHFR, methylenetetrahydrofolate reductase; NSAID, non-steroidal anti-inflammatory drug; NSP, non-starch polysaccharides; OS, oligosaccharides; RS, resistant starch; SCFA, short-chain fatty acids; tHcy, total homocysteine; Val, valine.

* Corresponding author: Professor John Mathers, tel. +44 0191222 6912, fax +44 0191222 8684, email john.mathers@ncl.ac.uk 
Table 1. Summary of strength of evidence from epidemiological literature linking consumption of pulses with risk of cancer at eleven sites (World Cancer Research Fund/American Institute of Cancer Research, 1997)

\begin{tabular}{llc}
\hline Site & Strength of evidence & Judgement \\
\hline Breast & Limited and inconsistent & $\mathrm{X}$ \\
Colon and rectum & Inconsistent & $\mathrm{X}$ \\
Endometrium & Limited & $\mathrm{X}$ \\
Larynx & Very limited & $\mathrm{X}$ \\
Lung & Limited and inconsistent & $\mathrm{X}$ \\
Mouth and pharynx & Inconsistent & $\mathrm{X}$ \\
Nasopharynx & Very limited & $\mathrm{X}$ \\
Oesophagus & Limited & $\mathrm{X}$ \\
Ovary & One study only & $\mathrm{X}$ \\
Pancreas & Limited and inconsistent & $\mathrm{X}$ \\
Prostate & Limited & $\mathrm{X}$ \\
\hline
\end{tabular}

$\mathrm{X}$, No judgement possible.

In its report Nutritional Aspects of the Development of Cancer, the UK's Committee on Medical Aspects of Food and Nutrition Policy had little to say about the relationship between intakes of pulses and cancer risk (Department of Health, 1998). The potential benefits of higher intakes of vegetables and of fruits were explored in detail, but pulses (and potatoes) were excluded from the definition of vegetables, on the grounds that pulses 'are generally regarded as starchy foods, having a different place in the diet' (Department of Health, 1998).

\section{The epidemiological challenge}

There is substantial evidence (Doll \& Peto, 1981; Willett, 1995) that variation in diet can account for about onethird of the variation in cancer incidence worldwide and that diets rich in plant foods are associated with reduced risk of cancer at most sites (World Cancer Research Fund/American Institute of Cancer Research, 1997; Department of Health, 1998). An ecological study in China found that residents of a low-risk area for gastric cancer consumed kidney beans, raw vegetables, fruit, tomatoes and soya products more frequently than those in a high-risk area (Takezaki et al. 1999). Some casecontrol studies have provided evidence of protection by pulses against cancer of the colon and rectum (Franceschi, 1999) and prostate (Jain et al. 1999), whereas others have reported no protection against breast cancer (Potischman et al. 1999) and an increased risk of endometrial cancer (Tzonou et al. 1996). In the large Netherlands Cohort Study, consumption of pulses was associated with a reduced risk of prostate cancer (relative risk, 0.71; $95 \%$ CI 0.51, 0.98) (Schuurman et al. 1998) but had no effect on risk of stomach cancer (Botterweck et al. 1998). NonHispanic white Seventh-day Adventists living in California who consumed red meat had significant protection against colon cancer if they consumed legumes frequently (Frazer, 1999). Legume consumption was also associated with lowered $(P=0.01)$ risk of cancer of the pancreas (Frazer, 1999). The results of rodent studies have been equivocal. For example, in F344 rats treated with azoxymethane to induce colonic tumours, replacing casein with pinto beans (Phaseolus vulgaris) and adjusting the diet to ensure similar fat and protein contents resulted in significantly fewer rats with colon cancer and reduced tumour multiplicity (Hughes et al. 1997). In contrast, feeding a diet containing chickpeas (Cicer arietinum) and wheat compared with casein and wheat led to greater tumour mass index (log transformed sum of tumour areas per rat) in male Sprague-Dawley rats injected with the procarcinogen dimethylhydrazine (McIntosh et al. 1998).

Despite the fact that at least 58 studies have reported results for intakes of pulses and cancer risk (World Cancer Research Fund/American Institute of Cancer Research, 1997), it will be very difficult, using conventional epidemiological tools, to ascertain the quantitative contribution made by pulses to cancer risk. Several factors underlie this problem, including:

1. The diversity of pulses. Pulses are the fruits and seeds of several leguminous plants eaten over a wide range of stages of botanical maturity, resulting in considerable heterogeneity in chemical composition. However, most pulses consumed as human food are the dry seeds of grain legumes, rich in protein and in starch.

2. The diversity of pulse-containing food products. Although some pulses are eaten after very little processing, e.g. boiled immature peas, others, e.g. soyabeans, are processed extensively by mechanical or microbiological means before inclusion in many other food products, e.g. ice cream, bakery goods or meat substitutes.

3. Low intakes of pulses, especially in economically developed countries. Together with nuts and seeds, pulses provide only $2.4 \%$ and $5.6 \%$ of total energy intake in economically developed and developing countries respectively (World Health Organization, 1990).

4. Co-correlation of intakes. Because of the ways in which pulses are used in many cuisines, it will be very difficult to distinguish possible effects of pulses from those of foods with which the pulses are consumed commonly, e.g. other vegetables or components of stews.

The challenge is to develop alternative approaches that will provide more robust estimates of intakes of pulses. Molecular epidemiology may offer a way forward. For example, it may be possible to identify compounds in urine or plasma (Adlercreutz et al. 1991; Stumpf et al. 2000) which could form the basis for quantitative measures of exposure to specific pulses or to pulses in general. Considerable progress in this direction has already been made in respect of certain plant secondary metabolites. The apparently protective effect of increased soyabean intake against cancer of the breast and prostate (Stephens, 1999) is supported by studies showing lower odds ratio for breast cancer with increasing excretion of equol and enterolactone (Ingram et al. 1997) which are phyto-oestrogens in high concentrations in soyabeans.

\section{Genetic basis of cancer}

Approximately one-third of people in the UK are known to develop tumours, and cancer accounts for about onequarter of deaths. The large majority of cancers arise in later life as a result of a complex interplay between inherited 
susceptibility/resistance genes, nutritional and other exposures during development in utero and life-style factors (Fig. 1). In this conceptual model, an individual's complement of genes establishes the fulcrum from which the 'health pendulum' is suspended, and thus has a major effect in determining the likelihood that that an individual will remain cancer free despite poor nutrition in utero and/or a high-risk life-style. Although there are celebrated examples where the inheritance of a mutated copy of a single gene is the major determinant of cancer risk (familiar cancers; Table 2), most cancers are 'sporadic' in that the aetiologically important genetic mutations are acquired as somatic events in individual stem cells.

It is believed that there are around 3 million polymorphisms in the human genome and these are the basis for each individual's phenotypic characteristics. Although not all of these polymorphisms will prove to be functional, those that are may contribute to a person's susceptibility/resistance to cancer through interactions with environmental factors such as diet. For example, homozygous carriage of a variant form of the folate-metabolizing enzyme, 5,10methylenetetrahydrofolate reductase (MTHFR; ${ }^{667} \mathrm{C} \rightarrow \mathrm{T}$, $\mathrm{Ala} \rightarrow \mathrm{Val})$ is associated with a $50 \%$ reduction in risk of colorectal cancer (CRC) compared with homozygous normals or heterozygous genotypes. However, this apparent protection is absent in men with folate deficiency or in

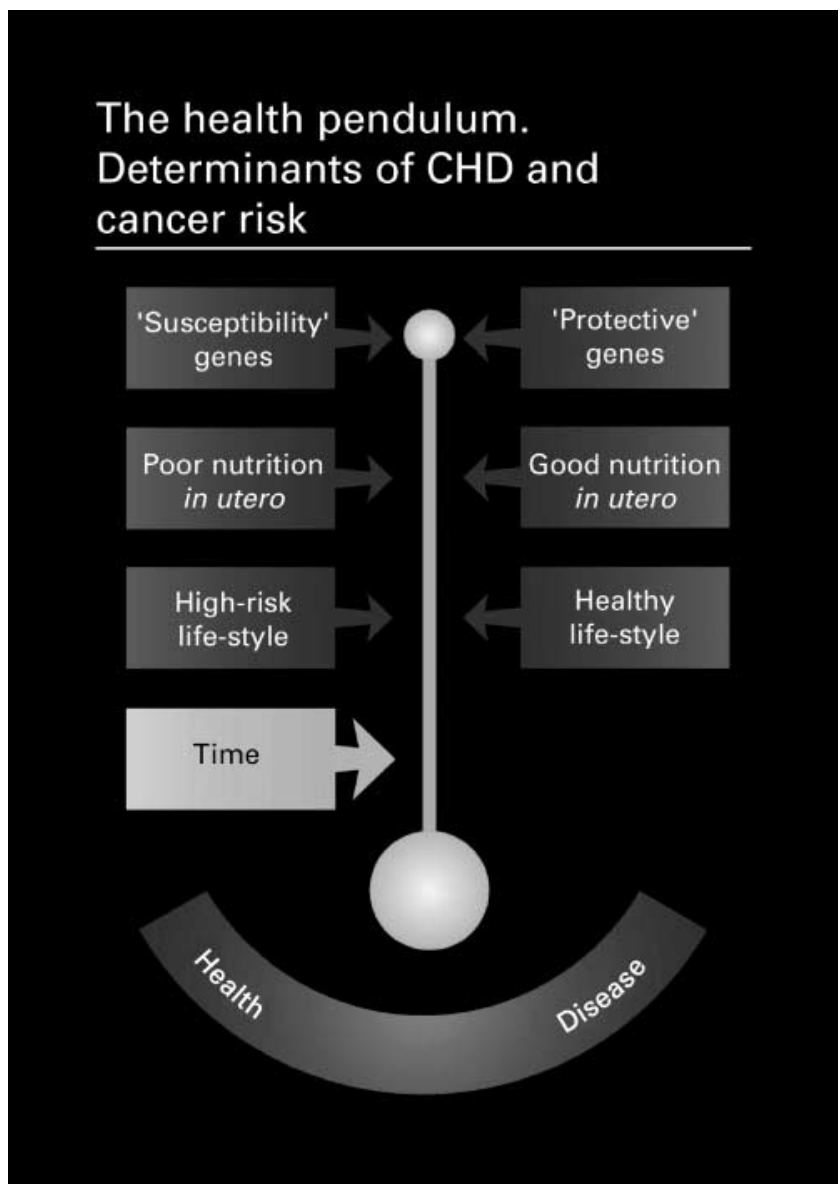

Fig. 1. Conceptual model of factors influencing cancer and cardiovascular disease risk. those consuming one or more alcoholic drinks/d (Ma et al. 1997). In addition, those homo- or heterozygous for the Ala $\rightarrow$ Val form of the MTHFR enzyme have significantly higher concentrations of plasma total homocysteine (tHcy) when riboflavin status is low (Hustad et al. 2000). Since raised circulating concentration of tHcy is a good marker for inadequate folate status, an argument can be made that there will be an interaction between dietary riboflavin supply and carriage of the variant form of MTHFR in determining CRC risk. Another example of diet-gene interactions comes from a polymorphism in the manganese superoxide dismutase (MnSOD) gene, where there is a $\mathrm{T}$ to $\mathrm{C}$ substitution in the mitochondrial targeting sequence resulting in a $\mathrm{Val} \rightarrow$ Ala change in the signal peptide. This gives rise to inefficient targeting of the MnSOD protein to the mitochondrion. In premenopausal women, those with the Val variant have a greater risk of breast cancer than homozygotes for the common form of the gene and this increased risk is exacerbated if the women have low intakes of fruits and vegetables (Ambrosone et al. 1999). It seems likely that protection against oxidative stress is inherently lower in people with the Val variant of MnSOD.

\section{Prevention of cancer}

Strategies for the prevention of cancer are likely to be more successful if they are based on a sound understanding of biological basis of cancer. This will include:

1. the genetic basis of cancer (discussed above);

2. the importance of the balance between damage to the cell's macromolecules, especially the genome, and the extent of repair; and

3. phenotypic characteristics which distinguish tumour cells from normal cells.

The genome is exposed to damage by endogenous and exogenous agents, especially those causing oxidative damage or alkylation, and by copying errors during mitosis. This damage is sensed by complex machinery, which includes p53, leading to cell cycle arrest and repair or cell killing by apoptosis. Oxygen radicals are generated endogenously, e.g. by immune cells, and supplied exogenously in foods. The most reactive species is the hydroxyl radical, which generates $8-0 x 0-G$ when in reaction with DNA. A range of antioxidant enzymes, including the glutathione peroxidases and superoxide dismutases, provide a first line of defence of the genome by breaking down oxygen radicals and other oxidative species such as $\mathrm{H}_{2} \mathrm{O}_{2}$. A second line of defence is provided by the cell's DNA repair mechanisms, of which there are five, including: base excision repair, nucleotide excision repair, direct repair, post-replication repair and mismatch repair.

Tumours arise from clonal expansion of a mutated stem cell that has acquired a competitive advantage in the Darwinian sense. Tumour cells have lost the normal controls on cell proliferation, fail to differentiate and become insensitive to apoptotic signals. For solid tumours to grow, they must initiate new blood vessel growth (angiogenesis) to provide nutrients and oxygen for the increasing cancer mass. Tumour cells may be 'invisible' to the immune system or actively defend themselves against immune 
Table 2. Examples of genes in which inherited mutations are the major determinants of cancer risk

\begin{tabular}{llll}
\hline Gene & Chromosome & \multicolumn{1}{c}{ Function of gene product } & Cancer site \\
\hline$A P C$ & $5 \mathrm{q} 21$ & $\begin{array}{l}\text { Multiple functions, including integration } \\
\text { of intracellular signalling }\end{array}$ & Colon and rectum* \\
$h M L H 1$ & $3 \mathrm{p} 21.3$ & DNA mismatch repair & Colon† \\
$B R C A 2$ & $13 q 12-q 13$ & Tumour suppressor & Breast \\
$R B 1$ & $13 q 14$ & Control of cell proliferation & Retina \\
\hline
\end{tabular}

${ }^{*}$ Also associated with tumours at extracolonic sites.

† Major risk of endometrial cancer in women. One of five/six genes encoding the consortium of DNA mismatch repair proteins.

attack (Armstrong \& Mathers, 2000). Metastases occur when further mutations of the tumour cells provide the capacity for invasion of the underlying tissues and for travel to distant sites via the blood, lymph or body cavities. Although much has been learned about the biology of cancer from studies of tumour cells alone, recognition of the heterogeneity of cell types making up tumours will be important for future studies aimed at developing effective strategies for cancer prevention or for chemotherapy (Hanahan \& Weinberg, 2000).

\section{Pulses as sources of anti-cancer compounds}

Although chemoprevention of cancer is in its infancy and most of the definitive trials to date have demonstrated no benefit (Lippmann et al. 1998), there is a growing arsenal of drugs and food-derived substances which show considerable promise in in vitro studies, animal models and small-scale human trials (Singh \& Lippmann, 1998a,b). Substances with potential as cancer-preventing compounds are likely to have one or more of the following properties:

1. prevent DNA damage;

2. enhance DNA repair;

3. augment apoptosis of damaged cells;

4. improve immunosurveillance;

5. reduce tumour growth, e.g. by preventing angiogenesis;

6. prevent metastases.

Non-steroidal anti-inflammatory drugs (NSAIDs), e.g. aspirin, are among the most promising chemopreventative agents against CRC (Waddell \& Loughry, 1983; Elder \& Paraskeva, 1997). There is very consistent evidence from observational studies that frequent and sustained consumption of aspirin provides approximately $50 \%$ protection against CRC in both women and men (Thun et al. 1991; Giovannucci et al. 1995) and intervention studies to test the efficacy of aspirin are under way (see, for example, Burn et al. 1998). The mechanism of the putative anticancer effect of aspirin is unknown, but may be related to its ability to inhibit cyclooxygenase (COX) (Marnett, 1992). COX-2 is upregulated in inflammation and in tumours, and COX-2-specific inhibitors such as celecoxib reduce intestinal tumorigenesis in rodent models (Jacoby et al. 2000) and reduce polyp recurrence in familial adenomatous polyposis (FAP) patients (Steinbach et al. 2000). FAP patients develop multiple large-bowel polyps because they have a germ-line mutation in one allele of the $A P C$ gene, the gatekeeper for CRC (Polakis, 1997). NSAIDs may protect against colon and other cancers by inhibiting angiogenesis through COX-2-dependent mechanisms. However, there are several other potential routes to tumour suppression, including stimulation of apoptosis via upregulation of Bcl- $\mathrm{X}_{\mathrm{L}}$ (a member of the B-cell lymphoma, Bcl-2, family of proteins) or suppression of release of the transcription factor NF- $\kappa$ B by downregulating phosphorylation of its inhibitor I- $\mathrm{KB}$ (Anonymous, 2001).

Pulses contain a wide range of nutrients and non-nutrient bioactive microconstituents that may be protective against cancer (Table 3) when consumed in sufficient quantities. Of particular interest are the carbohydrates in pulses. Pulses are rich in starch which, because of the way it is packaged in starch granules and its relatively high content of amylose, is only slowly digested in the small bowel, so that substantial quantities flow to the large bowel as resistant starch (RS) (Asp et al. 1996). There is a strong negative correlation between the intake of starch and risk of CRC (Cassidy et al. 1994) and it has been hypothesized that it is the RS fraction which conveys protection. The nonstarch polysaccharide (NSP) and oligosaccharide (OS) fractions of pulses also provide substrates for the largebowel microflora, and there is ample evidence that the RS, NSP and OS in peas and beans are extensively fermented within that organ (Goodlad \& Mathers, 1990; Key \& Mathers, 1995). Adding cooked haricot beans (P. vulgaris) to white-bread-based diets produced a marked shift in the pattern of short-chain fatty acids (SCFA) in the caecal contents of rats, with an almost threefold increase in the molar proportion of butyrate (Key \& Mathers, 1995). It is not known whether this increase in butyrate can be attributed directly to the altered substrate supply, but there is evidence for greater proportions of butyrate when the transit time through the large bowel is reduced (Mathers \& Dawson, 1991). Consumption of pulses and bread is associated with faster transit through the intestine in women (Probert et al. 1995). Studies in which the RS intake was increased by feeding raw potato starch to rats

Table 3. Examples of potential protective components against cancer provided by pulses

\begin{tabular}{ll} 
Nutrients & Bioactive microconstituents \\
\hline Resistant starch & Protease inhibitors \\
Non-starch polysaccharides & Saponins \\
Oligosaccharides & Phytosterols \\
Folates & Lectins \\
Selenium & Phytates \\
Zinc &
\end{tabular}


demonstrated a curvilinear relationship between RS intake and proportion of butyrate in caecal SCFA (Mathers et al. 1997), suggesting that there may be an optimum intake of RS to maximize large-bowel butyrate. There is very extensive evidence from in vitro studies that butyrate may be antineoplastic, since it suppresses the growth of tumour cells and induces apoptosis (Hague et al. 1996). Butyrate also appears to enhance immunosurveillance (Bonnotte et al. 1998). Direct administration of butyrate to the colon reduced tumour multiplicity and tumour size in carcinogen-treated rats (D'Argenio et al. 1996). The mechanistic explanation for these antineoplastic effects of butyrate remains obscure but may relate to the action of butyrate as a histone deacetylase inhibitor (Wu et al. 2001). Acetylation of the histone 'tails' leads to DNA compaction and gene silencing, so inhibition of acetylation would be expected to prevent these morphological changes and to induce gene expression (Siavoshian et al. 2000).

Prevention of DNA damage and/or enhancement of DNA repair are promising strategies for reducing cancer risk. As indicated in Table 3, pulses are useful sources of a number of micronutrients ( $\mathrm{Se}$ and $\mathrm{Zn}$ ) and non-nutrient bioactive substances (phytates) which may improve antioxidant defences. While there is good understanding of the biological mechanisms of DNA repair, there has been little study of the effects of dietary (or other environmental) agents on the efficacy of these processes.

It is probable that the mechanisms of action of some of the constituents of pulses will be similar to those being identified for pharmaceutical agents such as the NSAIDs. However, there may be important (if subtle) differences in molecular mechanisms between nutrients and drugs, as illustrated by a recent study (Mariadason et al. 2000) that used microarray-based techniques to compare the pattern of gene expression in a CRC cell line treated with butyrate and sulindac (an NSAID). Both agents suppress growth and enhance apoptosis of cancer cells, but the patterns of gene expression, and therefore the signalling pathways involved, were significantly different. Butyrate (but not sulindac) appeared to shunt the cells along the normal irreversible pathway of maturation leading to cell death and the authors suggest that this feature may mean that nutrients such as butyrate may be safer (from a toxicological perspective) for long-term chemopreventative use (Mariadason et al. 2000).

\section{Future research strategies}

The World Cancer Research Fund/American Institute of Cancer Research (1997) made the following recommendation for future research in respect of pulses:

'Given the nutritional content of pulses and their importance in plant-based diets as rich sources of protein and of bioactive microconstituents that may protect against cancer, high priority should be given to epidemiological and experimental studies in which pulses are carefully identified and measured and their relation to disease risk established.'

For the reasons outlined earlier, it is likely to be difficult, using conventional epidemiological approaches, to establish the relationship (if any) between intake of pulses and cancer risk. Progress may be made if such studies focus on 'populations where consumption is higher and more varied than has usually been the case in the studies to date' (World Cancer Research Fund/American Institute of Cancer Research, 1997).

Important information may also be obtained from welldesigned animal studies, particularly using mouse models genetically engineered to develop tumours spontaneously, i.e. without the need to administer potent carcinogens (Moser et al. 1990; Fodde et al. 1994). There are a number of such mouse models for intestinal neoplasia, which have proved to be sensitive to both drugs and food components (Beazer-Barclay et al. 1996; Kennedy et al. 1996; Wasan et al. 1997; Williamson et al. 1999). This approach has the added advantage of facilitating mechanistic investigations that may help identify classes of compounds derived from pulses that have anti-tumour activity. For example, the isoflavonoid curcumin has been shown to suppress development of intestinal tumours (Huang et al. 1997) possibly by release and activation of NF-кB and upregulation of apoptosis (Collett et al. 2001).

However, results from such murine models may not always be a reliable guide to effects in human subjects. Although epidemiological studies suggest that soya isoflavones are protective against cancer of the breast and colon (Tuyns et al. 1988; Lee et al. 1991; Lamartiniere, 2000; Lu et al. 2000), there was no protection against intestinal neoplasia when soya isoflavones were included at up to $475 \mathrm{mg} / \mathrm{kg}$ diet in a Western-type high-risk diet (high fat, low dietary fibre and calcium) fed to $A p c^{\text {Min }}$ mice (Sørensen et al. 1998). The most convincing evidence for the role (if any) of pulses in cancer prevention will come from human intervention trials. Although there have been a number of such trials using nutrients as the intervention agent and with cancer as the endpoint (Lippmann et al. 1998), the difficulties and cost of undertaking such trials (need for large number of subjects compliant with the intervention over several years) mean that it is unlikely that trials with pulses as the intervention agent will be carried out. Of greater practicality are intervention studies using surrogate (or intermediate) endpoints, but reliable pre-cancer endpoints are much less well developed than with cardiovascular disease where, for example, blood lipid concentrations, blood pressure and haemostatic factors have been validated as intermediate endpoints (Mathers, 2000). Aberrant crypt foci show promise as a surrogate endpoint for CRC (Takayama et al. 1998) and it is likely that the explosion of research using post-genomic technologies will result in the development of molecular pre-malignant markers of risk, which could be used as surrogate endpoints in human intervention trials.

In summary, pulses include a diverse array of low-fat foods rich in a number of components likely to be beneficial in reducing the risk of cancers at several sites. Despite being eaten widely, the amounts consumed are often small. This, together with the diversity in the nature of pulses and the lack of robust data on intakes, has resulted in a paucity of convincing evidence from epidemiological studies for protection by pulses against 
cancer at any site. Future epidemiological studies should focus on those populations with higher intakes and should incorporate biological markers of exposure to pulses. Once reliable surrogate endpoints for specific cancers have been validated, it should be possible to design informative human intervention studies.

\section{Acknowledgements}

Cancer prevention studies in my laboratory are supported by the Medical Research Council (GO100496), the Biotechnology and Biological Sciences Research Council (13/D15232, 13/D15721), the Food Standards Agency (N12002, N12005, N12006) and the World Cancer Research Fund (2001/37, 2001/38).

\section{References}

Adlercreutz H, Fotsis T, Bannwart C, Wahala K, Brunow G \& Hase $\mathrm{T}$ (1991) Isotope dilution gas chromatographic-mass spectrometric method for the determination of lignans and isoflavonoids in human urine, including identification of genistein. Clinica Chimica Acta 199, 263-278.

Ambrosone CB, Freudenheim JL, Thompson PA, Bowman E, Vena JE, Marshall JR, Graham S, Laughlin R, Nemoto Y \& Shields PG (1999) Manganese superoxide dismutase $(\mathrm{MnSOD})$ genetic polymorphisms, dietary antioxidants, and risk of breast cancer. Cancer Research 59, 602-606.

Anonymous (2001) Anti-inflammatories inhibit cancer growth but how? Science 291, 581-582.

Armstrong F \& Mathers JC (2000) Kill and cure: dietary augmentation of immune defences against colon cancer. Proceedings of the Nutrition Society 59, 215-220.

Asp N-G, van Amelsvoort JMM \& Hautvast JGAJ (1996) Nutritional implications of resistant starch. Nutrition Research Reviews 9, 1-31.

Beazer-Barclay Y, Levy DB, Moser AR, Dove WF, Hamilton SR, Vogelstein B \& Kinzler KW (1996) Sulindac suppresses tumorigenesis in the Min mouse. Carcinogenesis 17, 1757-1760.

Bonnotte B, Favre N, Reveneau S, Micheau O, Droin N, Garrido C, Fontana A, Chauffert B, Solary E \& Martin F (1998) Cancer cell sensitization to fas-mediated apoptosis by sodium butyrate. Cell Death Differentiation 5, 480-487.

Botterweck AA, van den Brandt PA \& Goldbohm RA (1998) A prospective cohort study on vegetable and fruit consumption and stomach cancer risk in The Netherlands. American Journal of Epidemiology 148, 842-853.

Burn J, Chapman PD, Bishop DT \& Mathers J (1998) Diet and cancer prevention: the Concerted Action Polyp Prevention (CAPP) Studies. Proceedings of the Nutrition Society 57, $183-186$.

Cassidy A, Bingham SA \& Cummings JH (1994) Starch intake and colorectal cancer risk: an international comparison. British Journal of Cancer 69, 937-942.

Collett GP, Robson CN, Mathers JC \& Campbell FC (2001) Curcumin modifies $A p c^{\min }$ apoptosis resistance and inhibits 2amino 1-methyl-6-phenylimidazo[4,5-b] pyridine (PhIP) induced tumour formation in $A p c^{m i n}$ mice. Carcinogenesis 22, 101-104.

D'Argenio G, Cosenza V, Delle Cave M, Iovino P, Delle Valle N, Lombardi G \& Mazzacca G (1996) Butyrate enemas in experimental colitis and protection against large bowel cancer in a rat model. Gastroenterology 110, 1727-1734.
Department of Health (1998) Nutritional Aspects of the Development of Cancer. Report of Health and Social Subjects 48. London: The Stationery Office.

Department of Health (1999) Saving Lives: Our Healthier Nation. London: The Stationery Office.

Doll R \& Peto R (1981) The causes of cancer: quantitative estimates of avoidable risks of cancer in the United States today. Journal of the National Cancer Institute 66, 1191-1308.

Elder DJE \& Paraskeva C (1997) NSAIDs to prevent colorectal cancer: a question of sensitivity. Gastroenterology 113, 1999-2003.

Fodde R, Edelmann W, Yang K, van Leeuwen C, Carlson C, Renault B, Breukel C, Alt E, Lipkin M, Khan PM \& Kucherlapati R (1994) A targeted chain termination mutation in the mouse Apc gene results in multiple intestinal tumours. Proceedings of the National Academy of Sciences USA 91, 8969-8973.

Franceschi S (1999) Nutrients and food groups and large bowel cancer in Europe. European Journal of Cancer Prevention $\mathbf{8}$, Suppl. 1, S49-S52.

Frazer GE (1999) Associations between diet and cancer, ischemic heart disease, and all-cause mortality in non-Hispanic white California Seventh-day Adventists. American Journal of Clinical Nutrition 70, 532S-538S.

Giovannucci E, Egan KM, Hunter DJ, Stampfer MJ, Colditz GA, Willett WC \& Speizer FE (1995) Aspirin and the risk of colorectal cancer in women. New England Journal of Medicine 333, 609-614.

Goodlad JS \& Mathers JC (1990) Large bowel fermentation in rats given diets containing raw peas (Pisum sativum). British Journal of Nutrition 64, 569-587.

Hague A, Butt AJ \& Paraskeva C (1996) The role of butyrate in human colonic epithelial cells: an energy source or inducer of differentiation and apoptosis? Proceedings of the Nutrition Society 55, 937-943.

Hanahan D \& Weinberg RA (2000) The hallmarks of cancer. Cell 100, 57-70.

Huang MT, Newmark HL \& Frenkel K (1997) Inhibitory effects of curcumin on tumourigenesis in mice. Journal of Cell Biochemistry Suppl. 27, 26-34.

Hughes JS, Ganthavorn C \& Wilson-Sanders S (1997) Dry beans inhibit azoxymethane-induced colon carcinogenesis in F344 rats. Journal of Nutrition 127, 2328-2333.

Hustad S, Ueland PM, Vollset SE, Zhang Y, Bjørke-Monsen AL \& Schneede J (2000) Riboflavin as a determinant of plasma total homocysteine: Effect modification by the methylenetetrahydrofolate reductase C677T polymorphism. Clinical Chemistry 46, 1065-1071.

Ingram D, Sanders C, Kolybaba M \& Lopez D (1997) Case-control study of phyto-oestrogens and breast cancer. Lancet 350, 990-994.

Jacoby RF, Seibert K, Cole CE, Kelloff G \& Lubet RA (2000) The cyclooxygenase- 2 inhibitor celecoxib is a potent preventive and therapeutic agent in the Min mouse model of adenomatous polyposis. Cancer Research 60, 5040-5044.

Jain MG, Hislop GT, Howe GR \& Ghadirian P (1999) Plant foods, antioxidants, and prostate cancer risk; findings from case-control studies in Canada. Nutrition and Cancer 34, 173-184.

Kennedy AR, Beazer-Barclay Y, Kinzler W \& Newberne PM (1996) Suppression of carcinogenesis in the intestines of Min mice by the soybean-derived Bowman-Birk inhibitor. Cancer Research 56, 679-682.

Key FB \& Mathers JC (1995) Digestive adaptations of rats given white bread and cooked haricot beans (Phaseolus vulgaris): large-bowel fermentation and digestion of complex carbohydrates. British Journal of Nutrition 74, 393-406. 
Lamartiniere CA (2000) Protection against breast cancer with genistein: a component of soy. American Journal of Clinical Nutrition 71, Suppl., 1705S-1707S.

Lee HP, Gourley L, Duffey SW, Esteve J, Lee J \& Day NE (1991) Dietary effects on breast cancer risk in Singapore. Lancet 337 , 1197-1200.

Lippmann SM, Lee JJ \& Sabichi AL (1998) Cancer chemoprevention: progress and promise. Journal of the National Cancer Institute 90, 1514-1527.

Lu L-JW, Anderson KE, Grady JJ, Kohen F \& Nagamani M (2000) Decreased ovarian hormones during a soya diet: implications for breast cancer prevention. Cancer Research 60, $4112-4121$.

Ma J, Stampfer MJ, Giovannucci E, Artigas C, Hunter DJ, Fuchs C, Willett WC, Selhub J, Hennekens CH \& Rozen R (1997) Methylenetetrahydrofolate reductase polymorphism, dietary interactions, and risk of colorectal cancer. Cancer Research 57, 1098-1109.

McIntosh GH, Wang YHA \& Royle PJ (1998) A diet containing chickpeas and wheat offers less protection against colon tumours than a casein and wheat diet in dimethylhydrazinetreated rats. Journal of Nutrition 128, 804-809.

Mariadason JM, Corner GA \& Augenlicht LH (2000) Genetic reprogramming in pathways of colonic cell maturation induced by short chain fatty acids: Comparison with trichostatin A, sulindac, and curcumin and implications for chemoprevention of colon cancer. Cancer Research 60, 4561-4572.

Marnett LJ (1992) Aspirin and the potential role of prostaglandins in colon cancer. Cancer Research 52, 5575-5589.

Mathers JC (2000) Food and cancer prevention: human intervention studies. In Dietary Carcinogens and Antimutagens. Chemical and Biological Aspects, pp. 395-403 [IT Johnson and GR Fenwick, editors]. Cambridge: Royal Society of Chemistry.

Mathers JC \& Dawson LD (1991) Large bowel fermentation in rats eating processed potatoes. British Journal of Nutrition 66, 313-329.

Mathers JC, Smith H \& Carter S (1997) Dose:response effects of raw potato starch on small intestinal escape, large-bowel fermentation and gut transit time in the rat. British Journal of Nutrition 78, 1015-1029.

Moser AR, Pitot HC \& Dove WF (1990) A dominant mutation that predisposes to multiple intestinal neoplasia in the mouse. Science 247, 322-324.

Polakis P (1997) The adenomatous polyposis coli (APC) tumor suppressor. Biochimica Biophysica Acta 1332, F127-F147.

Potischman N, Swanson CA, Coates RJ, Gammon RD, Brogan DR, Curtin J \& Brinton LA (1999) Intake of food groups and associated micronutrients in relation to early-stage breast cancer. International Journal of Cancer 82, 315-321.

Probert CS, Emmett PM \& Heaton KW (1995) Some determinants of whole-gut transit time: a population-based study. Quarterly Journal of Medicine 88, 311-315.

Schuurman AG, Goldbohm RA, Dorant E \& van den Brandt PA (1998) Vegetable and fruit consumption and prostate cancer risk: a cohort study in The Netherlands. Cancer Epidemiology, Biomarkers and Prevention 7, 873-880.

Siavoshian S, Segain JP, Kornprobst M, Bonnet C, Cherbut C, Galmiche JP \& Blottiere HM (2000) Butyrate and trichostatin A effects on the proliferation/ differentiation of human intestinal epithelial cells: induction of cyclin D3 and p21 expression. Gut 46, 507-514.

Singh DK \& Lippmann SM (1998a) Cancer chemoprevention. Part 1: Retinoids and carotenoids and other classic antioxidants. Oncology 12, 1643-1653, 1657-1658.

Singh DK \& Lippmann SM (1998b) Cancer chemoprevention.
Part 2: Hormones, nonclassic antioxidant natural agents, NSAIDs and other agents. Oncology 12, 1787-1800.

Sørensen IK, Kristiansen E, Mortensen A, Nicolaisen GM, Wijnands JAH, van Kranen HJ \& van Kreijl CF (1998) The effect of soy isoflavones on the development of intestinal neoplasia in the Apc ${ }^{\mathrm{Min}}$ mouse. Cancer Letters 130, 217-225.

Steinbach G, Lynch PM, Phillips RKS, Wallace MH, Hawk E, Gordon GB, Wakabayashi N, Saunders B, Shen Y, Fujimura T, Su L-K, Levin B, Godio L, Patterson S, Rodriguez-Bigas MA, Jester SL, King KL, Schumacher M, Abbruzzese J, DuBois RN, Hittelman WN, Zimmerman S, Sherman JW \& Kelloff G (2000) The effect of celecoxib, a cyclooxygenase-2 inhibitor, in familial adenomatous polyposis. New England Journal of Medicine 342, 1946-1952.

Stephens FO (1999) The rising incidence of breast cancer in women and prostate cancer in men: A possible preventive role for nature's sex hormone modifiers - the phytoestrogens (Review). Oncology Reports 6, 865-870.

Stumpf K, Pietinen P, Puska P \& Adlercreutz H (2000) Changes in serum enterolactone, genistein, and diadzein in a dietary intervention study in Finland. Cancer Epidemiology, Biomarkers and Prevention 9, 1369-1372.

Takayama T, Katsui S, Takahasi Y, Ohi M, Nojiri S, Sakamaki S, Kato J, Kogawa K, Miyaki H \& Niitsu Y (1998) Aberrant crypt foci of the colon as precursors of adenoma and cancer. New England Journal of Medicine 339, 1277-1284.

Takezaki T, Gao CM, Ding JH, Liu TK, Li MS \& Tajima K (1999) Comparative study of lifestyles of residents in high and low risk areas for gastric cancer in Jiangsu Province, China; with special reference to allium vegetables. Journal of Epidemiology 9, 297-305.

Thun MJ, Namboodiri MM \& Heath CW (1991) Aspirin use and reduced risk of fatal colon cancer. New England Journal of Medicine 325, 1593-1596.

Tuyns AJ, Kaaks R \& Haelterman M (1988) Colorectal cancer and the consumption of foods: a case-control study in Belgium. Nutrition and Cancer 11, 189-204.

Tzonou A, Lipwoth L, Kalandidi A, Trichopoulou A, Gamatsi I, Hsieh CC, Notara V \& Trichopoulos D (1996) Dietary factors and the risk of endometrial cancer: a case-control study in Greece. British Journal of Cancer 73, 1284-1290.

Waddell WR \& Loughry RW (1983) Sulindac for polyposis of the colon. Journal of Surgical Oncology 24, 83-87.

Wasan HS, Novelli M, Bee J \& Bodmer WF (1997) Dietary fat influences on polyp phenotype in multiple intestinal neoplasia mice. Proceedings of the National Academy of Sciences USA 94, 3308-3313.

Willett WC (1995) Diet, nutrition and avoidable cancer. Environmental Health Perspectives 103, Suppl. 8, 165-170.

Williamson SLH, Kartheuser A, Coaker J, Dehghan Kooshkghazi M, Fodde R, Burn J \& Mathers JC (1999) Intestinal tumorigenesis in the Apc $1638 \mathrm{~N}$ mouse treated with aspirin and resistant starch for up to 5 months. Carcinogenesis 20, 805-810.

World Cancer Research Fund/American Institute of Cancer Research (1997) Food, Nutrition and the Prevention of Cancer: a global perspective. Washington: World Cancer Research Fund/American Institute of Cancer Research.

World Health Organization (1990) Diet, Nutrition and the Prevention of Chronic Diseases. Report of a WHO study group. Technical Report Series 797. Geneva: World Health Organization.

Wu JT, Archer SY, Hinnebusch B, Meng S \& Hodin RA (2001) Transient vs. prolonged histone hyperacetylation: effects on colon cancer cell growth, differentiation, and apoptosis. American Journal of Physiology, Gastrointestinal and Liver Physiology 280, G482-G490. 